\title{
FURTHER EVIDENCE SUPPORTING THE RE- PLACEMENT OF THE FEDERAL TAX SYSTEM WITH A CONSUMPTION TAX BASE
}

Julia K. Brazelton, College of William and Mary

\begin{abstract}
This study examines the primary considerations accompanying implementation of a consumption-based federal tax system. Additionally, theoretical and empirical (including graphs, derivatives, and regression analysis) techniques are used to evaluate a consumption tax structure in the United States. The evidence presented supports such a system; however, the public's misperceptions concerning the impact and mechanics and the legislative body's unwillingness to entertain a consumption tax proposal will probably further delay serious consideration for replacement of the income tax with a consumption tax.
\end{abstract}

\section{Introduction}

There are many goals of Federal tax policy: (1) to raise revenue, (2) to stimulate economic growth, (3) to provide equitable treatment of taxpayers, (4) to provide aid through social programs, and (5) to instill positive attitudes among the public, to name just a few. One of the most difficult tasks of policy-makers is to devise a tax system in which there are satisfactory relationships among all of the objectives of the system. Tax policy research produces conflicting results with respect to the supremacy of any one tax system. This is evidenced in a recent statement by Porcano: "While many taxpayers believe the current system is inequitable, they do not agree about the causes of the inequity. An unfortunate aspect of a tax system is that because of varying objectives, it is discriminatory by nature." $<1>$

The present federal income tax system is suboptimal. It violates all of the characteristics comprising a good tax structure: vertical and horizontal equity, accomplishment of economic incentives, administrative ease and efficiency. The individual income tax can best be characterized as a progressive wage tax, accompanied by a penal- ty $\operatorname{tax}$ on the realization of a modest amount of nominal income from capital and a subsidy for borrowing. $<2>$ Comprehensive tax reform is imperative to rectify the shortcomings of the current system of taxation. A consumption tax base provides a practicable alternative.

\section{Theoretical Justification}

There are many arguments favoring and opposing a consumption tax system. In this section, several reasons are presented which support a cashflow system (i.e., tax is levied on the difference between income and savings or investment for each period). A Treasury study, Blueprints for Basic Tax Reform, recognizes that a consumption tax base is less widely advocated than an income tax base; but, the study concludes that a consumption tax constitutes a viable option and should be seriously considered. This cash flow tax proposal outlined in the Treasury study treats (the) definition of the filing unit, exemptions for family size, and deductions of personal consumption items the same way as the comprehensive income tax proposal. The differences between the two proposals are in the treatment of items which repre- 
sent a change in net worth, or income from capital, and in the treatment of gifts and inheritances. $<3>$

Galper and Steuerle assert that saving incentives have been incorporated into the Internal Revenue Code to facilitate a healthy rate of economic growth; but, the saving incentives present in current legislation are not systematically effective. According to Galper and Steuerle, one of the goals of structural tax reform should be to increase household saving. These researchers state that saving just may not be very responsive to tax changes that increase after-tax rewards. They delineate three criteria which incentives must satisfy to have the potential to increase after-tax rewards, submitting that a consumption tax, if properly drafted, is able to satisfy these criteria:

1. Tax benefits should not go to taxpayers who simply switch assets from one form of saving to another. The shift of assets into a tax-preferred form permits taxpayers to achieve tax reductions with no increase in their saving.

2. No tax provision can be considered a true incentive if it does not apply at the margin. A deduction with a capthat is, one with a limit on the amount of deduction or exclusion permittedprovides little marginal incentive for a person already receiving income in excess of the maximum.

3. A tax incentive for saving must provide symmetrical treatment of positive saving on the one hand and negative saving or borrowing on the other. $<4>$

The primary difference between an income and a consumption base is in the treatment of savings. The present tax structure penalizes the saver and encourages borrowing. Why should the individual burdened more by the income tax be the one who saves the most?
This has been a consideration for hundreds of years, yet without resolve, as seen in the following eighteenth century quote from Thomas Hobbes' Leviathan:

For what reason is there, that he which laboureth much, and sparing the fruits of his labour, consumeth little, should be more charged than he that living idlely, getteth, little, and spendeth all he gets; seeing the one hath no more protection from the Commonwealth, then the other? $<5>$

It is argued that a consumption tax would appear to be superior to an income tax base since cash flow is much simpler to measure than the accretion of wealth used in the current tax structure. In addition to this substantial simplification, a consumption basis could result in a fairer and more efficient distribution of the tax burden. However, it is necessary to remember that the difference between an income and a consumption based tax structure is deferral, that is, the timing of the inclusion of an item in income. Under current law, deferral of income is permitted only in certain cases. The treatment of deferred income would become more uniform under the consumption tax since the proceeds from all sales of investment items would be taxed only when consumed.

Also, double taxation results in an income-based system when a taxpayer saves and then incurs further tax on his savings. So, the amount of tax, in aggregate, is larger for the saver than for the consumer. Consider, for example, two individuals who are in identical pre-tax positions. Under an income tax system, the individual who saves will be subject to a greater tax. However, under a consumption tax system, the higher consumer will pay a higher tax. Exhibit I presents a comparison of taxation in a two-period model under consumption and income bases (modified from $<6>$ ). This exhibit demonstrates the discrimination in- 
herent in an income tax system. In an income tax system, an individual who saves is penalized, as seen in taxpayer B's present values of consumption and tax (10 percent discount rate assumed).

Furthermore, the principles of vertical and horizontal equity can be implemented in a consumption tax system. Horizontal equity requires equal tax treatment for individuals in equal lifetime positions. Vertical equity requires differential tax treatment among individuals in unequal lifetime positions (i.e., individuals with greater long-term ability should pay more). The argument that a consumption tax may remove some of these shortcomings is generally regarded as one of the most compelling for its implementation. Violation of the horizontal equity rule would cause individuals in equal circumstances unequal treatment. In the current income-based system, not all accumulations of wealth are taxed, so there is not horizontal neutrality. This is one aspect which can be corrected by a consumption tax structure.

Another related problem is tax incidence. For instance, given equal amounts of income, it is more likely that young people, large families, the unhealthy, and the elderly will have larger consumption to income ratios. Elimination of the inequities imposed by retention of deductions for these high consumers, while also removing the deductions for all other high consumers, would necessarily and immediately complicate the system.

Another justification for taxing consumption as opposed to income is "that it is more just to tax someone on the value of what he takes out of society in terms of the goods and services which he consumes, than on the

\section{EXHIBIT I}

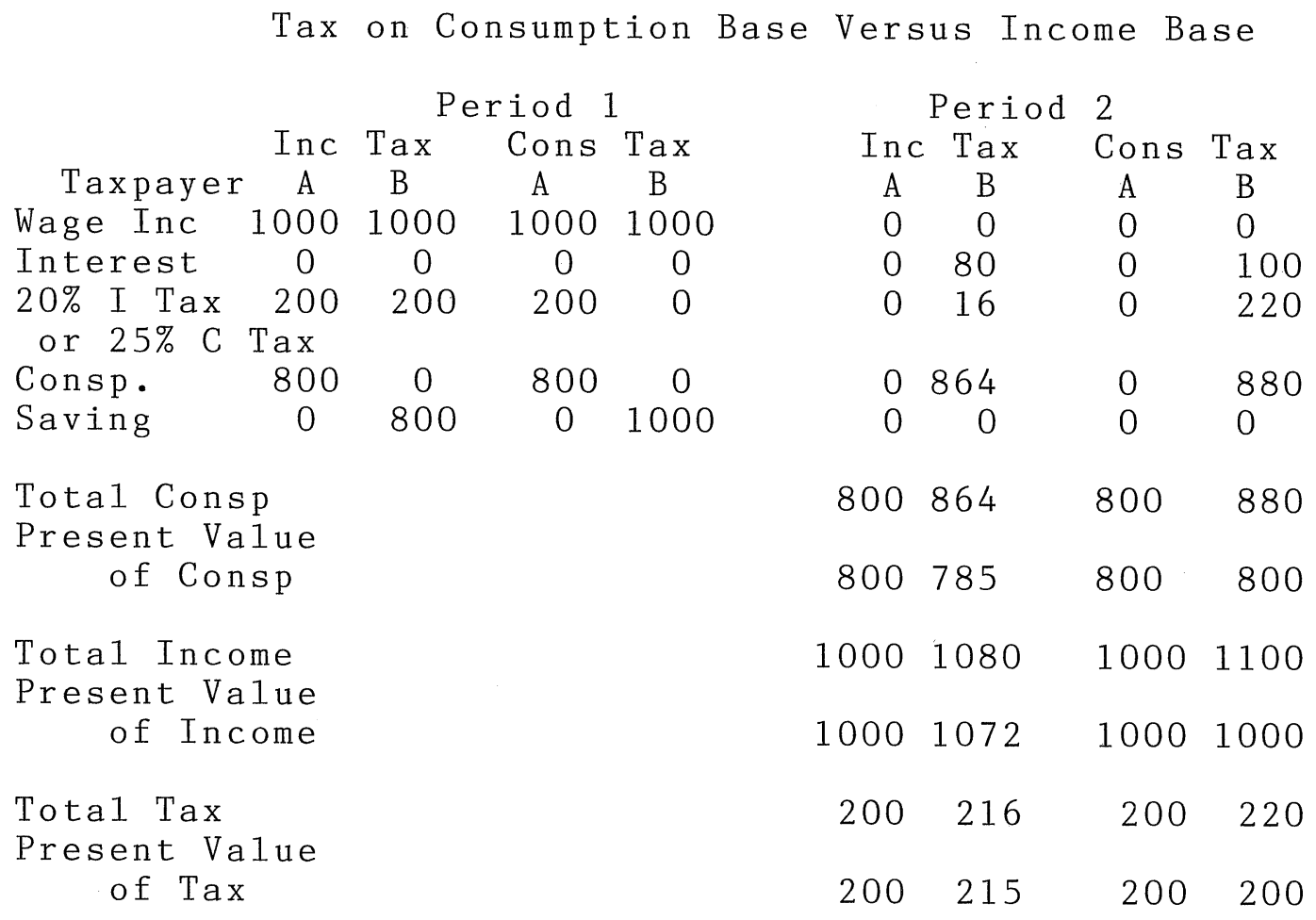


value of what he contributes to society." <7>

The final, and a particularly prevalent element which prohibits an effective tax structure based on income, is inflation. Currently, a taxpayer is shifted from one tax bracket to another when taxed on investment proceeds, while not gaining any purchasing power; thus, the individual is actually falling behind as a result of the increase in taxes. Also, an investment which grows in nominal dollars may not have grown in real dollars. The first problem could be solved by implementation of either an income or a consumption tax and by indexing the parameters of the tax calculation. A consumption tax basis could eliminate this second shortcoming of the current system, because calculation of the current year's tax involves only current year transactions in current year dollars.

\section{Results}

The purpose of data analysis in this paper is to present some evidence of both the feasibility and the limitations encountered in a consumption tax system. Cross-sectional data gathered by the Bureau of Labor Statistics provides the source for examining several hypotheses. The depth of this research caused by inadequate data prevents any sound conclusions; instead, it encourages future research undertaken to assess the full impact of a consumption tax. While there are many methods for testing the hypotheses, multiple regression techniques, calculus, and supporting graphics proved most effective.

The Bureau of Labor Statistics' Survey of Consumer Expenditures provides the data source for examination of the five hypotheses. The population from which the Bureau of Labor Statistics sample is drawn consists of the civilian noninstitutional population, including military personnel living off post. The information provided by the Bureau of Labor Statistics includes income ranges, average incomes before and after taxes, a corresponding consumption amount, the number of members in the household, and the educational levels. (Other information is provided, but is omitted from this list because it is not utilized in this study.)

It is expected that as income increases, consumption decreases. This phenomenon is attributable to the fact that once necessities are covered, the amount of income consumed slows as income increases; simultaneously, investment/savings increases as the need to consume decreases. To test the hypothesis that APC is a decreasing function of income, Exhibit II is constructed. It is evident from this data that APC is decreasing as income increases. The graph in Exhibit III depicts this relationship as well.

In the analysis of the second hypothesis, which states that the MPC differs among individuals (attributable to differing needs), various forms of an equation stating that consumption is a function of income were regressed. The results of some of these regressions are presented in Exhibit IV. Statistical significance of the parameter estimates is indicated at the .0001 level by an asterisk. The standard errors and R-squares for the models are also presented with the resultant equations.

While Equation (1) is statistically significant, the sum of the squared residuals indicates nonlinearity; therefore, with inclusion of INCSQ, the nonlinear specification yielded a statistically significant coefficient on the squared variable. An examination of this information presented in graphical form confirms the results. The points in Exhibit $\mathrm{V}$ represent the actual values; the solid lines correspond to the estimated equations and are labeled as such.

Using the first derivative of the natural $\log$ function of equation (2) (see Equation (3) in Exhibit III), the 


\begin{tabular}{cc}
\multicolumn{2}{c}{ Exhibit II } \\
Average Propensities to Consume \\
Consumption & APC \\
$\$ 3,044$ & 1.78 \\
4,011 & 1.15 \\
4,539 & 1.01 \\
5,116 & .93 \\
5,750 & .89 \\
6,165 & .82 \\
6,944 & .77 \\
7,926 & .72 \\
8,929 & .67 \\
10,500 & .61 \\
12,665 & .57 \\
14,628 & .54 \\
16,838 & .52 \\
17,712 & .48 \\
17,285 & .40 \\
22,575 & .28
\end{tabular}

Exhibit III

Decreasing Average Propensities to Consume

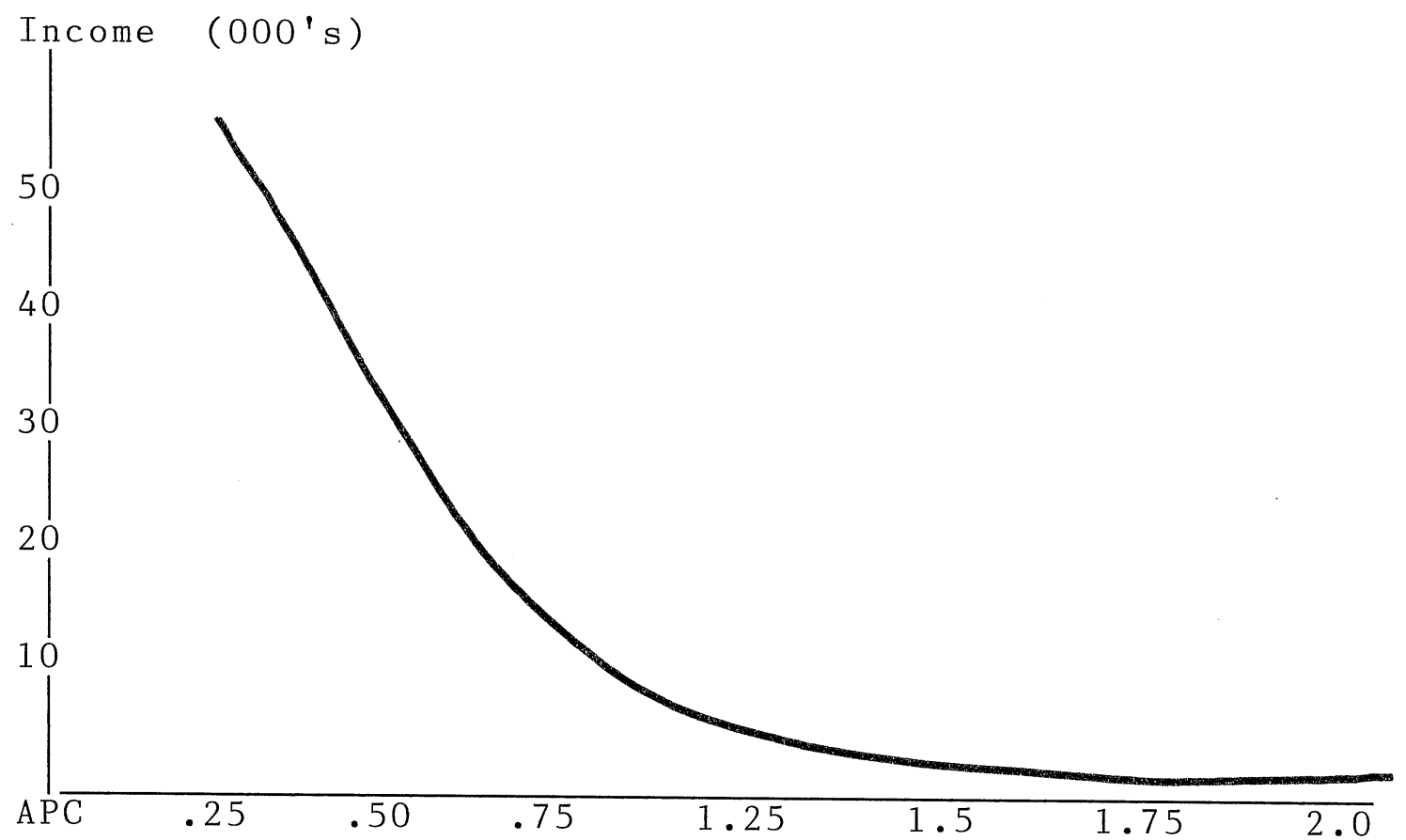


The Journal of Applied Business Research - Vol. 4, No. 1

Exhibit IV

Results of Regression Analysis

Consumption is a function of :

\begin{tabular}{|c|c|c|c|c|c|c|c|c|c|}
\hline Equation & Inter & $\underset{*}{\operatorname{Inc}}$ & Incsq & $\mathrm{Y}$ & Ysq & Size & Educ & $\begin{array}{l}\mathrm{R} \\
80\end{array}$ & $\begin{array}{l}\text { SSE } \\
57935030\end{array}$ \\
\hline 2 & $*$ & $*$ & $*$ & & & & & .99 & 4111735 \\
\hline 3 & $*$ & & & $*$ & $*$ & & & .99 & .0488 \\
\hline 4 & $*$ & $*$ & & & & $*$ & & .91 & 80284012 \\
\hline 5 & $*$ & $*$ & $*$ & & & & $*$ & .99 & 187726 \\
\hline 6 & $*$ & $*$ & $*$ & & & & & .99 & 569484 \\
\hline
\end{tabular}

Legend:

Inter $=$ Intercept

Inc $=$ Income

Incsq= Square of Income Term
$Y=$ Natural Log of Income

Ysq $=$ Natural Log of Income Squared

Size= Number of Members in Household

Educ $=$ Educational Level of Head of Household

\section{Exhibit V}

Graphs of Estimating Equations

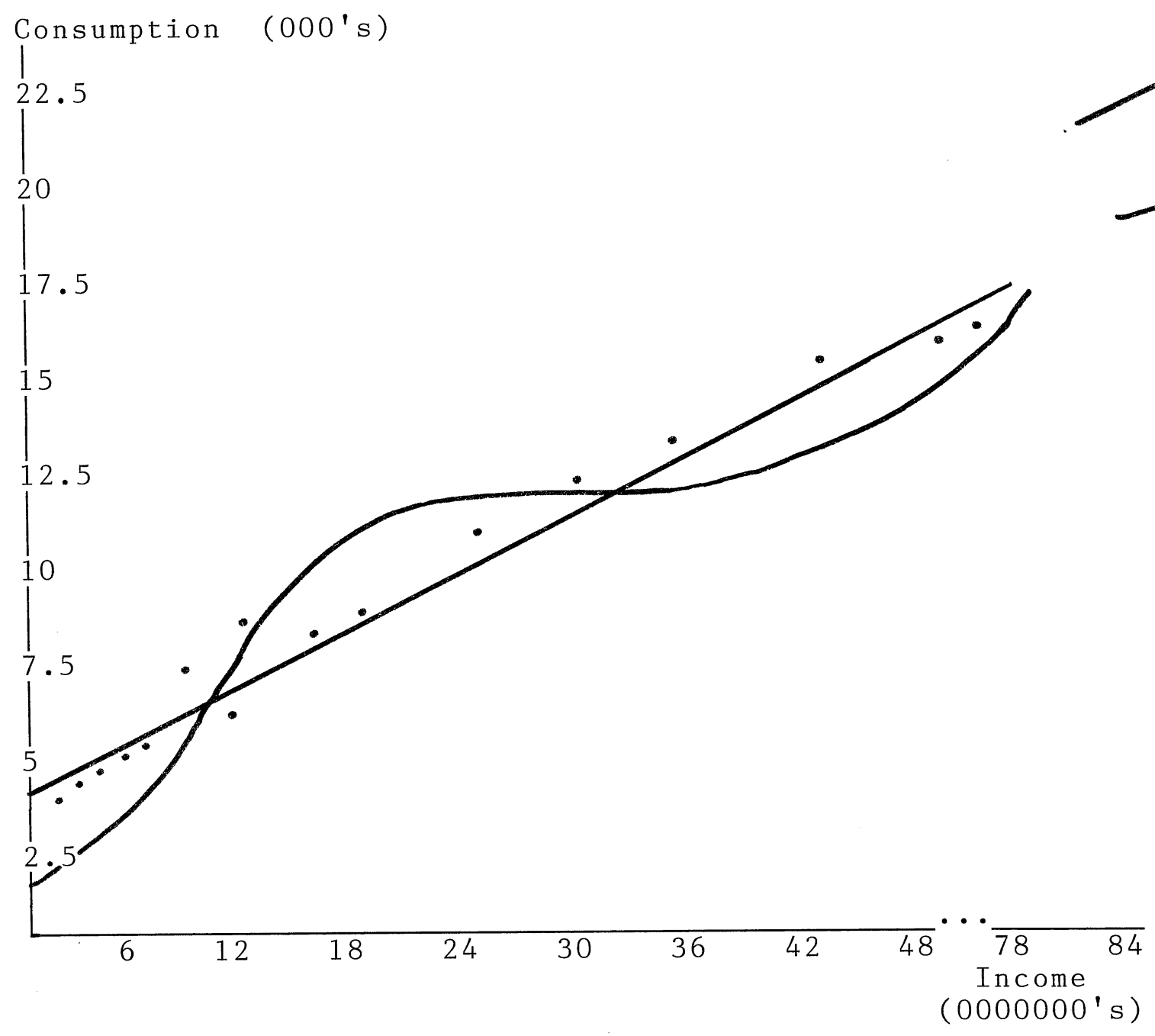


short-run MPCs are derived for each income bracket. The results are presented in Exhibit VI.

The results in Exhibit VI are consistent with economic theory concerning preferences. The negative MPC of the top income bracket is questionable, however. A plausible explanation involves the BLS sample. Because the category, "Over $\$ 50,000, "$ encompasses such a diverse range of incomes, from $\$ 50,001$ to $\$ 50,000,000$, it is likely that consumption and savings are drastically overstated for individuals in the lower end of the range. Ignoring this limitation, the results provide more evidence in the search for proof that the MPC is an increasing function of income.

Testing the next hypothesis, which states that the number of members in the household is a factor assisting in the determination of consumption, leads to a visual observance of the phenomenon in Exhibit VII.

The regression results obtained when adding a variable, SIZE (the number of members in the household), confirm the intuitive observation determined in the previous exhibit. There are 72 observations in this model; but, because all income levels above $\$ 25,000$ have been summarized into a single observation, the squared income term was not statistically significant. The results of the estimating equation appear in Exhibit IV, Equation (4). These results imply the need for a personal and dependency exemption, a zero bracket amount, or a standard deduction, as an allowance for the increased basic consumption.

Finally, the prediction that the educational level of the head of the household is inversely related to consumption for a given level of income was validated using a regression model, (5), including another variable, EDUC. Because educational level is a significant determinant of consumption, educated persons would retain some advantage in a consumption tax system, if for no other reason than their ability to seek competent tax advice, thus lowering their taxable consumption.

\section{Limitations}

Issues affecting the reliability of the results are discussed extensively in this section. The primary shortcoming in this study is the use of aggregated data. Terza has addressed some of the problems associated with using data in which averages and income categories are utilized. He suggests a weighting technique which remains faithful to the underlying probability structure, assumed to be normally distributed. For this reason, a simple weighting technique was employed to assure that the results achieved using averages for income and expenditures are consistent with the underlying actual observation.

The results achieved in the weighted model confirm those previously indicated. The standard errors of the coefficients are substantially reduced by this weighting procedure. The fit is improved, although it is not as noticeable as the reduction in the standard errors. Model (6) is presented in Exhibit IV. The BLS evidence presented supports the hypothesis of differing marginal propensities to consume; however, the need for time series analysis is apparent here. With a sample size of sixteen and use of a single year, the results are not totally reliable.

The results achieved in this investigation imply that the consumption function is nonlinear for this particular point in time. Certainly these conclusions can be easily criticized on the basis that there are only sixteen observations, all from averages for consumption and income; however, the results are significant because the models are all consistent with theory. Income is positively related to consumption, while, the square of the income term is inversely related, implying that savings 
Exhibit VI

Marginal Propensities to Consume

INCOME LEVEL

Under $\$ 3,000$

$3,000-3,999$

4,000- 4,999

$5,000-5,999$

$6,000-6,999$

$7,000-7,999$

$8,000-9,000$

$10,000-11,999$

$12,000-14,999$

$15,000-19,999$

$20,000-24,999$

$25,000-29,9.99$

$30,000-34,999$

$35,000-39,999$

40,000-49,999

Over $\$ 50,000$
SHORT-RUN MPC

.5248

.5120

.5048

.4977

.4906

.4833

.4727

.4584

.4408

.4133

.3782

.3422

.3061

.2701

.2233

$-.0363$

Exhibit VII

Relationship of Household Size to Consumption

Income Range

Under \$3,000

3,000- 3,999

4,000- 4,999

5,000- 5,999

$6,000-6,999$

$7,000-7,999$

$8,000-9,999$

$10,000-11,999$

$12,000-14,999$

$15,000-19,999$

20,000-24,999

Over $\$ 25,000$
Members in Household

1

1.529

1.004

.839

.763

.753

.697

.643

.630

.580

.517

.459

.326
2

2.081

1.204

1.094

.938

.881

.807

.750

.665

.604

.559

.481

.374
4

$$
2.453
$$

1.286

1. 162

1.003

.967

.909

.800

.758

.663

.607

.573

.419

3.083
1.462

1. 164

1.076

.967

.866

.837

.755

.702

.655

.601

.462
5

3.094

1. 345

1.108

1. 295

1.106

.961

.895

.789

.703

.655

.612

.501
$6+$

3.022

1.402

1.196

1.118

1.071

.914

.949

.827

.772

.700

.646

.499 
increases as income increases. Also, as expected, there is a positive relationship between consumption and the number of members in the household. Finally, as hypothesized, educational level is inversely related to consumption.

There are several other limitations inherent in a study of this nature, two of which have been mentioned previously: the use of averages to validate the hypotheses and the sample size. The first problem is eliminated through the use of a weighting technique. Second, the population from which the Bureau of Labor Statistics sampled is very large; here, very small samples, designed to be representative of the population, are used. The sample from which this is derived is, however, statistically significant, thus, eliminating the sample size problem. Also ignored is the simultaneity of the consumption function. The simultaneity problem is particularly apparent in the model which incorporates education. The question which arises is, "Does education cause consumption or does it cause income, which, in turn, causes consumption?" The short-run implications of the MPC for high income individuals is less than for lower income families.

Another limitation arises as a result of the sample- the systematic addition of a single variable to the model. Although this procedure is not preferred, data limitations necessitated it (i.e., different average incomes were presented for consumption, education, family size, etc.).

Finally, the short-run MPCs in the BLS data were significantly higher than corresponding IRS data MPCs. There are two explanations which may account for this: (1) IRS data does not employ averages and (2) nonfilers and nonitemizers also consume.

\section{Conclusions}

The present federal income tax system is ineffective as an economic stimulant. The need for comprehensive tax reform is apparent:

Sustained high inflation during the 1970 s increased effective rates of taxation, particularly those on reported income from capital. The income tax system, with its particular definition of taxable income and a graduated tax rate structure, had been designed for an economy of relative price stability... The inflation of the 1970s sharply distorted the measure of taxable income earned from capital. Taxation of capital income drives a wedge between the private (after-tax) return on capital and social (before-tax) return. $<8>$

In the long-run, it is difficult to ascertain the response to a predicted rise in domestic saving. Economists disagree on the sufficiency of increased saving to ensure an increased rate of capital formation. Incentives to increase business investment must accompany provisions to encourage domestic saving to supplant the purpose of the policy.

Presently, it is not clear how a change to a consumption base would affect aggregate saving. The substitution or price effect is assumed to increase the net interest return and, thus, an expected shift to saving. Would this possible increase in aggregate saving result in higher unemployment rates? In advanced capitalist economies such as Japan and West Germany, which have higher propensities to save $\langle 9\rangle$, the inducement for investment has offset unemployment and advanced capital formation. How would the allocation of resources be affected? What would happen to nonprofit organizations such as universities and churches if there were no charitable contribution deduction? Would a consumption tax, in the long-run, result in regressivity in the tax structure? Would this system result in higher marginal tax rates during retirement years? Would the transitional problems 
be too great to overcome? Would the government be able to control the saving and consumption rates through tax rates? Would the uncertainty created by a mass structural change create economic problems worse than the current situation? Could this tax structure provide more revenue at lower tax rates than those currently in effect, since, intuitively, more taxes would be collected from the high-bracket taxpayer? To collect the same amount of revenue, it is hypothesized $<10\rangle$ that, in the long-run, a much higher tax rate would have to be imposed to account for the exemption of savings.

The feasibility of a change to a consumption base is questionable. At present, accountants are familiar with the tax system. The costs to retrain and educate these tax professionals would be substantial. The Internal Revenue Service would be forced to implement a similar retraining program. Although the measurement of income would encounter the same avoidance problems under the revised system, it would still require the formulation of new techniques to assess the overstatement of saving. The new system would be subjected to political pressures from the public, as well as the private sector. However, because of electronic devices used by the government and practitioners, the costs may not be insurmountable.

Furthermore, measurement and definition of saving, prevention of tax evasion, equitable treatment of taxpayers in the long-run, and the difficulties involved with any change must be overcome. However, the argument that in addition to measuring income, we would also have to measure saving, is unfounded. True, we would have to measure income, but would it not be easier to measure saving (verification through the invested institution) and qualified investments than deductions allowed in the current system, however unlikely the cessation of itemization may be.

The consumption tax fulfills the requirements of a good tax system delineated by most tax policy experts. It is superior to the current, incomebased system in every arena. Are the rich currently paying their fair share? Most taxpayers in the middle income bracket would say, "No." Although their MPC is lower, the upper-bracket individuals would not be able to participate in tax avoidance schemes as they are currently known. A consumption tax system would encourage investment and discourage dissaving, unlike the current income-based structure. The consumption system would be more understandable to the common man- that is, there would be much less arbitrariness. Certainly, a consumption tax system would be an effective reform measure. With much empirical research, the economic benefits may become as clear as the theoretical benefits. 


\section{Footnotes}

1. Porcano, p. 619.

2. Steuerle, p. 300.

3. U.S. Treasury, p. 12.

4. Galper and Steuerle, p. 2.

5. Hobbes.

6. Musgrave and Musgrave, pp. 245-246.

7. Kay and King, p. 76.

8. Bosworth, pp. 7, 24.

9. Seidman, p. 14.

10. Pechman, p. 198.

\section{References}

Bosworth, Barry P. Tax Incentives and Economic Growth. Washington, D.C.:The Brookings Institution, 1984.

Galper, Harvey and Eugene Steuerle. "Tax Incentives for Saving." Statistics of Income Bulletin, Department of the Treasury, Spring 1984.

Hobbes, Thomas. Leviathan. New York: Dutton, 1914.

Kay, J. A. and M. A. King. The British Tax System. Oxford: Oxford University Press, 1980.

Musgrave, Richard A. and Peggy B. Musgrave. Public Finance in Theory and Practice. New York: McGraw-Hill, Inc., 1980.

Pechman, Joseph A. Federal Tax Policy. Washington, D.C.: The Brookings Institution, 1977.

Porcano, Thomas M. "Distributive Justice and Tax Policy," The Accounting Review, October 1984, pp. 619-636.

Seidman, Laurence S. "The Personal Consumption Tax and Social Welfare," Challenge, September-October 1980, pp. 10-16.

U.S. Treasury Department. Blueprints for Basic Tax Reform. 1977. 